\title{
Long non-coding RNA bladder cancer-associated transcript 2 contributes to disease progression, chemoresistance and poor survival of patients with colorectal cancer
}

\author{
YONGJUN REN $^{1}$, CAIXIAZHAO ${ }^{2}$, YI HE $^{3}$, HAO XU $^{1}$ and XULI MIN ${ }^{1}$ \\ ${ }^{1}$ Department of Interventional Radiology, Sichuan Key Laboratory of Medical Imaging, The Affiliated Hospital of \\ North Sichuan Medical College; ${ }^{2}$ Department of Oncology, Nanchong Central Hospital; \\ ${ }^{3}$ Department of Gastrointestinal Surgery, The Affiliated Hospital of North Sichuan \\ Medical College, Nanchong, Sichuan 637000, P.R. China
}

Received October 18, 2018; Accepted February 20, 2019

DOI: 10.3892/ol.2019.10487

\begin{abstract}
Colorectal cancer (CRC) is one of the leading causes of cancer-associated mortality worldwide. Long non-coding RNAs (lncRNAs) have been revealed to modulate various biological cell processes, and are involved in the initiation and progression of different diseases, including CRC. However, the role of lncRNA bladder cancer-associated transcript 2 (BLACAT2) in CRC has not been defined. The present study aimed to investigate the role of BLACAT2 in CRC. The present study measured the expression levels of BLACAT2 in CRC cells and tissues by reverse-transcription-quantitative polymerase chain reaction, and associations among BLACAT2 expression levels, important clinicopathological parameters and patient survival were statistically evaluated. The functional role of BLACAT2 in metastasis, proliferation and drug resistance was also detected. BLACAT2 was overexpressed in CRC cells and tissues, and high BLACAT2 expression was associated with larger tumor size, and more advanced lymph node $(\mathrm{N})$, metastasis $(\mathrm{M})$ and tumor-NM stages. Additionally, survival analysis demonstrated that patients with high BLACAT2 expression exhibited poor overall survival. Notably, high BLACAT2 expression was identified as an independent risk factor for overall survival. Migration and invasion assays revealed that BLACAT2 promoted migration and invasion, respectively. In addition, overexpression of BLACAT2 increased colony numbers and optical density values of CRC cells in a colony formation assay and an MTT assay, respectively. Furthermore, BLACAT2 levels were
\end{abstract}

Correspondence to: Dr Yongjun Ren, Department of Interventional Radiology, Sichuan Key Laboratory of Medical Imaging, The Affiliated Hospital of North Sichuan Medical College, 63 Wenhua Road, Nanchong, Sichuan 637000, P.R. China

E-mail: yongjunrensc@sina.com

Key words: bladder cancer-associated transcript 2, metastasis, proliferation, drug resistance, prognosis significantly increased in 5-fluorouracil-resistant cells, and overexpression of BLACAT2 was markedly associated with a low cell inhibition rate. In conclusion, BLACAT2 overexpression may contribute to the metastasis, proliferation and chemoresistance of CRC cells, and high BLACAT2 expression may be a promising prognostic marker for patients with CRC.

\section{Introduction}

Colorectal cancer (CRC) is among the leading malignancies in terms of incidence rate and mortality rate worldwide (1). Despite the overall 5-year survival rate of patients with CRC increasing from 51 to $65 \%, \sim 30 \%$ of patients with stage I-III disease develop recurrent disease following initial treatment. In addition, $\leq 65 \%$ of patients with stage IV CRC relapse following curative treatment $(2,3)$. For patients with metastatic $\mathrm{CRC}$, there is a need for novel and individualized therapies in the third-line setting and beyond. Despite recent advances in the development of novel targeted therapies, there remains an unmet need to exploit oncogenic drivers of CRC and overcome acquired resistance. In addition, more efficient prognostic markers should be established, which can inform treatment decisions to avoid under- or over-treatment and to guide the intensity of patient follow-up.

Long non-coding RNAs (IncRNAs) belong to a large group of non-coding RNAs, and are generally classified as transcripts that are $200 \mathrm{nt}$ to $100 \mathrm{~kb}$ long, which lack the open-reading frame (4). lncRNA molecules are involved in diverse biological processes, including epigenetic regulation via molecular scaffolding, regulation of mRNA processing, molecular decoying and lncRNA-derived peptides through diverse mechanisms $(5,6)$. Notably, lncRNAs with highly specific expression patterns in certain tissues and diseases, including various types of cancer, have gained increasing interest as molecular targets for therapy $(7,8)$. Bladder cancer-associated transcript 2 (BLACAT2) is a novel lncRNA that was identified by $\mathrm{He}$ et al (9), who demonstrated that BLACAT2 is markedly upregulated in lymph node metastatic bladder cancer and that BLACAT2 is correlated with lymph node metastasis. Additionally, overexpression of BLACAT2 
promotes bladder cancer-associated lymphangiogenesis and lymphatic metastasis in cultured bladder cancer cell lines and mouse models (9). However, the expression pattern and functional role of BLACAT2 in other types of cancer, including $\mathrm{CRC}$, remain unknown.

The present study aimed to detect the expression of BLACAT2 in CRC cells and tissues. The clinical significance of BLACAT2 in CRC was explored. Additionally, the prognostic value of BLACAT2 was investigated. Functionally, the role of BLACAT2 in migration, invasion, proliferation and chemoresistance of CRC cells was investigated.

\section{Materials and methods}

Cell culture and transfection. A human intestinal epithelial cell line (HIEC-6) and CRC cell lines, including LOVO, SW620, HCT15, HCT116, SW480 and DLD1, were purchased from American Type Culture Collection (Manassas, VA, USA). LOVO and HCT15 cells were cultivated in Dulbecco's modified Eagle's medium (Gibco; Thermo Fisher Scientific, Inc., Waltham, MA, USA), and SW620, HCT116, SW480 and DLD1 cells were cultured in RPMI-1640 medium (Gibco; Thermo Fisher Scientific, Inc.). Media were supplemented with $10 \%$ fetal bovine serum (FBS; Gibco; Thermo Fisher Scientific, Inc.), $100 \mathrm{U} / \mathrm{ml}$ penicillin and $100 \mathrm{mg} / \mathrm{ml}$ streptomycin and cells were cultured at $37^{\circ} \mathrm{C}$ with $5 \% \mathrm{CO}_{2}$. HIEC-6 cells were cultured in OPTIMEM-GlutaMAX (Gibco; Thermo Fisher Scientific, Inc.) supplemented with 5\% FBS, 10 mM HEPES (Invitrogen; Thermo Fisher Scientific, Inc.) and $5 \mathrm{ng} / \mathrm{ml}$ epidermal growth factor (BD Biosciences, San Jose, CA, USA) at $37^{\circ} \mathrm{C}$ with $5 \% \mathrm{CO}_{2}$. BLACAT2 interference plasmids [pcDNA3.1-short hairpin RNA (sh)BLACAT2\#1 and pcDNA3.1-shBLACAT2\#2], a BLACAT2 overexpression plasmid (pcDNA3.1-BLACAT2) and control plasmids (pcDNA3.1-shControl and pcDNA3.1-Vector) were synthesized by Shanghai OE Biotech Co., Ltd. (Shanghai, China). Cells at 30-50\% confluence were transfected using Lipofectamine $^{\circledR} 2000$ (Invitrogen; Thermo Fisher Scientific, Inc.) in accordance with the manufacturer's protocols. The mass of plasmids was $0.8 \mu \mathrm{g}$. Cells were cultured for $48 \mathrm{~h}$ after transfection and harvested to determine transfection efficiency by reverse transcription-quantitative polymerase chain reaction (RT-qPCR), and then subjected to subsequent experimentation.

Clinical specimens. CRC tissues and paired normal colorectal tissues $(n=127)$ were collected between February 2012 and May 2016 at The Affiliated Hospital of North Sichuan Medical College (Nanchong, China). Normal tissues were located $\geq 2 \mathrm{~cm}$ away from the cancer tissues. All patients received surgical resection without neoadjuvant therapies. Patient characteristics are presented in Table I. Tumor-Node-Metastasis (TNM) staging was performed according to the American Joint Committee on Cancer guidelines (10). Tissue specimens were immediately snap-frozen and stored in liquid nitrogen until RNA extraction. Written informed consent was obtained from all patients. The present study was approved by the Ethics Committee of The Affiliated Hospital of North Sichuan Medical College. Follow-up was carried out regularly at the outpatient clinic. The end of the follow-up period was December 2017.
$R T$ - $q P C R$ assay. Total RNA from CRC cells and tissues was isolated using TRIzol ${ }^{\circledR}$ reagent (Invitrogen; Thermo Fisher Scientific, Inc.), according to the manufacturer's protocol. Total RNA $(1 \mu \mathrm{g})$ was used as a template for cDNA synthesis using a PrimeScript RT Reagent kit with gDNA Eraser (Takara Biotechnology Co., Ltd., Dalian, China). The temperature protocol for RT was as follows: $25^{\circ} \mathrm{C}$ for $5 \mathrm{~min}$, followed by $42^{\circ} \mathrm{C}$ for $60 \mathrm{~min}$ and $70^{\circ} \mathrm{C}$ for $5 \mathrm{~min}$. qPCR was performed using SYBR Premix Ex Taq (Takara Biotechnology Co., Ltd.). Briefly, qPCR was performed under the following conditions: $95^{\circ} \mathrm{C}$ for $5 \mathrm{~min}$, followed by 40 cycles of denaturation at $95^{\circ} \mathrm{C}$ for $30 \mathrm{sec}$, annealing at $60^{\circ} \mathrm{C}$ for $1 \mathrm{~min}$ and extension at $70^{\circ} \mathrm{C}$ for $1 \mathrm{~min}$. All RT-qPCR assays were performed on an ABI 7900 system (Applied Biosystems; Thermo Fisher Scientific, Inc.). GAPDH was utilized as an internal control. The primer sequences used were as follows: BLACAT2, forward 5'-GAG AGGGATCCACTCATCCA-3', reverse 5'-GGAAACAAA GGCAGAGCTT-3'; and GAPDH, forward 5'-CACCCACTC CTCCACCTTTG-3' and reverse 5'-CCACCACCCTGTTGC TGTAG-3'. The $2^{-\triangle \Delta C q}$ method was used to calculate the relative expression levels of BLACAT2 (11). Each experiment for the detection of mRNA expression levels in cells was repeated three times independently with triplicates.

Transwell migration and invasion assays. CRC cells (DLD1 and SW620) with BLACAT2 knockdown or overexpression and corresponding control cells were subjected to Transwell migration and invasion assays, to evaluate the effect of BLACAT2 on modulating migratory and invasive abilities. Briefly, cells $\left(3 \times 10^{4}\right)$ were suspended in serum-free RPMI-1640 medium $(200 \mu \mathrm{l})$ and seeded in the upper Transwell chamber $(8 \mu \mathrm{m}$ pore size; BD Biosciences, San Jose, CA, USA) with (for invasion assay) or without (for migration assay) Matrigel (BD Biosciences) precoating. Medium containing $20 \%$ FBS ( $700 \mu \mathrm{l}$ ) was added to the lower chamber to serve as a chemoattractant. Subsequently, the cells were incubated for $36 \mathrm{~h}$ at $37^{\circ} \mathrm{C}$. The cells in the upper chamber were then removed, and the migratory or invasive cells in the lower chamber were fixed with methanol for $20 \mathrm{~min}$ at room temperature, stained with $0.1 \%$ crystal violet solution for $20 \mathrm{~min}$ at room temperature and images were captured using a light microscope. Cells in five random fields were counted and the average number of migratory/invasive cells was utilized for comparison. Each experiment was repeated three times independently with triplicates.

Colony formation assay. Following transfection, CRC cells (500 cells/well) were seeded in 6-well plates and incubated for 10 days. Subsequently, colonies were fixed with methanol for $15 \mathrm{~min}$ and stained with $0.1 \%$ crystal violet for $15 \mathrm{~min}$ at room temperature. Colonies with diameters $>1 \mathrm{~mm}$ were counted under a light microscope (Olympus Corporation, Tokyo, Japan). Each experiment was repeated three times independently with triplicates.

MTT assay. An MTT assay was used for cell proliferation and cell inhibition rate analysis. CRC cells $(3,000$ cells/well) were plated in 96-well plates and transfection was performed. Subsequently, MTT (20 $\mu \mathrm{l}$; Sigma-Aldrich; Merck KGaA, Darmstadt, Germany) was added to each well at different time points $(0,24,48,72$ and $96 \mathrm{~h})$ and plates were incubated for 
Table I. Association between BLACAT2 expression and clinicopathological characteristics of patients with colorectal cancer.

\begin{tabular}{|c|c|c|c|c|}
\hline \multirow[b]{2}{*}{ Parameters } & \multirow[b]{2}{*}{ Number $(n=127)$} & \multicolumn{2}{|c|}{ BLACAT2 } & \multirow[b]{2}{*}{ P-value } \\
\hline & & Low $(\mathrm{n}=66)$ & High $(n=61)$ & \\
\hline Age & & & & 0.396 \\
\hline$<60$ years & 57 & 32 & 25 & \\
\hline$\geq 60$ years & 70 & 34 & 36 & \\
\hline Sex & & & & 0.122 \\
\hline Male & 68 & 31 & 37 & \\
\hline Female & 59 & 35 & 24 & \\
\hline CEA & & & & 0.803 \\
\hline$<4.5 \mu \mathrm{g} / \mathrm{ml}$ & 61 & 31 & 30 & \\
\hline$>4.5 \mu \mathrm{g} / \mathrm{ml}$ & 66 & 35 & 31 & \\
\hline Tumor location & & & & 0.369 \\
\hline Colon & 49 & 23 & 26 & \\
\hline Rectum & 78 & 43 & 35 & \\
\hline Differentiation grade & & & & 0.146 \\
\hline Well + Moderate & 75 & 43 & 32 & \\
\hline Poor + Undifferentiated & 52 & 23 & 29 & \\
\hline Tumor size & & & & 0.029 \\
\hline$<5 \mathrm{~cm}$ & 50 & 32 & 18 & \\
\hline$\geq 5 \mathrm{~cm}$ & 77 & 34 & 43 & \\
\hline T stage & & & & 0.674 \\
\hline $\mathrm{T} 1+\mathrm{T} 2$ & 67 & 36 & 31 & \\
\hline $\mathrm{T} 3+\mathrm{T} 4$ & 60 & 30 & 30 & \\
\hline $\mathrm{N}$ stage & & & & $<0.001$ \\
\hline No & 76 & 51 & 27 & \\
\hline N1 & 51 & 15 & 34 & \\
\hline M stage & & & & 0.028 \\
\hline M0 & 108 & 65 & 53 & \\
\hline M1 & 9 & 1 & 8 & \\
\hline TNM stage & & & & $<0.001$ \\
\hline I+II & 74 & 50 & 24 & \\
\hline III+IV & 53 & 16 & 37 & \\
\hline
\end{tabular}

BLACAT2, bladder cancer-associated transcript 2; CEA, carcinoembryonic antigen; M, metastasis; N, node; T, tumor.

an additional $4 \mathrm{~h}$ in a humidified incubator at $37^{\circ} \mathrm{C}$. Dimethyl sulfoxide $(100 \mu \mathrm{l} /$ well $)$ was added to each well to dissolve the formazan crystals followed by agitation of the plates for $10 \mathrm{~min}$ at room temperature. Optical density was measured at $492 \mathrm{~nm}$ using a microplate spectrophotometer (BioTek Instruments, Inc., Winooski, VT, USA). The cell inhibition rates were generated based on the cell viability following culturing of cells for $72 \mathrm{~h}$ with different concentrations $(0,10,20,30,40$ and $50 \mu \mathrm{g} / \mathrm{ml}$ ) of 5 -FU. Each experiment was repeated three times independently with triplicates.

Establishment of 5-fluorouracil (5-FU)-resistant cell lines. DLD1 and SW620 CRC cells at a confluence of 70\% were treated with 5-FU (5 $\mu \mathrm{g} / \mathrm{ml}$; Abcam, Cambridge, MA, USA) at room temperature. The surviving cells were cultured until they reached $80 \%$ confluence and were passaged twice. Sequentially increasing concentrations of 5-FU $(5 \mu \mathrm{g} / \mathrm{ml})$ were used to select 5-FU-resistant cells, and the concentration was finally maintained at $30 \mu \mathrm{g} / \mathrm{ml}$ for 2 months. 5-FU-resistant cells were used to evaluate the expression levels of BLACAT2 by RT-qPCR.

Statistical analysis. Data are expressed as the means \pm standard deviation and were analyzed using SPSS v19.0 software (IBM Corp., Armonk, NY, USA). Each experiment was performed in triplicate. A $\chi^{2}$ test was used to explore the associations between classified variables. The differences between two independent groups were analyzed with a Student's t-test. One-way analysis of variance followed by a least significance difference post hoc test was used to examine differences among three or more 
groups. To determine the cut-off value for distinguishing the specimens with high or low BLACAT2 expression, a receiver operating characteristic (ROC) curve was used. The point on the curve with the shortest distance to the coordinate $(0,1)$ was selected as the threshold value to classify cases as high or low expression. The Kaplan-Meier method was used to depict the overall survival (OS) curves, and the difference between the two groups was examined using the log-rank test. Univariate and multivariate analyses were conducted to analyze the risk factors for poor prognosis. $\mathrm{P}<0.05$ was considered to indicate a statistically significant difference.

\section{Results}

Overexpression of BLACAT2 is associated with CRC clinical progression. Measurement of BLACAT2 expression in CRC cells by RT-qPCR revealed that BLACAT2 was markedly upregulated in six CRC cell lines compared with in HIEC cells (Fig. 1A). Furthermore, expression of BLACAT2 was detected by RT-qPCR in 127 CRC tissues and paired normal tissues (Fig. 1B). As shown in Fig. 1C, CRC tissues exhibited higher BLACAT2 expression than paired normal tissues. In addition, BLACAT2 expression levels were statistically compared in CRC tissues of different clinical stages, and the results confirmed that CRC tissues of node (N)1/2 stage, metastasis (M)1 stage and TNM III/IV stage exhibited higher BLACAT2 expression than CRC tissues of N0 stage (Fig. 1D), M0 stage (Fig. 1E) and TNM I/II stage (Fig. 1F), respectively. These results demonstrated that BLACAT2 was overexpressed in $\mathrm{CRC}$ and may be associated with $\mathrm{CRC}$ clinical progression.

High BLACAT2 expression predicts poor OS in patients with $C R C$. To further verify the clinical significance of BLACAT2 in CRC, the 127 patients with CRC were divided into two groups: A low BLACAT2 expression group $(n=66)$ and a high BLACAT2 expression group $(n=61)$, based on the cutoff value (3.35) determined by ROC curve analysis (Fig. 2A). Subsequently, the associations between the clinicopathological features and BLACAT2 expression were statistically analyzed. The results revealed that high BLACAT2 expression was significantly associated with larger tumor size $(\mathrm{P}=0.029)$ and more advanced $\mathrm{N}$ stage $(\mathrm{P}<0.001)$, $\mathrm{M}$ stage $(\mathrm{P}=0.028)$ and TNM stage $(\mathrm{P}<0.001$; Table $\mathrm{I})$. In addition, the association between BLACAT2 expression and the OS rate was analyzed, which demonstrated that patients with high BLACAT2 expression had a poor OS rate compared with patients with low BLACAT2 expression ( $\mathrm{P}<0.001$; Fig. 2B).

The risk factors for poor prognosis of CRC were identified by univariate analysis, and it was revealed that advanced $\mathrm{N}$ stage $(\mathrm{P}<0.001), \mathrm{M}$ stage $(\mathrm{P}<0.001)$, TNM stage $(\mathrm{P}<0.001)$ and high BLACAT2 expression were risk factors for poor CRC prognosis (Table II). Further analysis of these factors with multivariate analysis identified that high BLACAT2 expression was an independent risk factor for CRC OS (hazard ratio $=1.164,95 \%$ confidence interval $=1.062-1.277, \mathrm{P}=0.001$; data not shown). In summary, BLACAT2 may be a promising prognostic marker for CRC.

IncRNA BLACAT2 accelerates the migration and invasion of CRC cells. To better understand the functional role of
BLACAT2 in CRC, BLACAT2 was silenced or ectopically overexpressed in DLD1 and SW620 cells (Fig. 3A and B), since the expression levels of BLACAT2 in these two cells lines were relatively moderate (Fig. 1A). In addition, the migratory and invasive abilities of CRC cells overexpressing BLACAT2, or in which BLACAT2 was silenced, were detected by Transwell migration and invasion assays. As expected, the interference of BLACAT2 in DLD1 and SW620 cells notably suppressed migration in the Transwell assay (Fig. 3C). Accordingly, the migration of DLD1 and SW620 cells with BLACAT2 overexpression was markedly increased (Fig. 3D). In addition, the invasive ability of DLD1 cells and SW620 cells exhibited a positive association with BLACAT2 levels (Fig. 3E and F). Overall, BLACAT2 promoted the migration and invasion of CRC cells.

IncRNA BLACAT2 contributes to the proliferation and chemoresistance of $C R C$ cells. The effect of BLACAT2 on CRC cell proliferation was investigated by colony formation and MTT assays. The colony numbers were greatly decreased in DLD1 and SW620 cells with BLACAT2 deficiency (Fig. 4A), whereas the colony numbers were markedly increased following BLACAT2 overexpression (Fig. 4B). In accordance with the colony formation assay, the MTT assay also demonstrated the role of BLACAT2 in promoting the proliferation of CRC cells (Fig. 4C and D).

Chemoresistance is a primary factor influencing the prognosis of patients with CRC, and the potential role of BLACAT2 in CRC chemoresistance was determined in the present study. First, 5-FU-resistant DLD1 and SW620 cells were established. In addition, the 5-FU-resistant DLD1 and SW620 cells exhibited much higher BLACAT2 expression than the untreated control DLD1 and SW620 cells, respectively. (Fig. 4E). Additionally, interference of BLACAT2 in DLD1 and SW620 cells significantly increased the cell inhibition rate as the concentration of 5-FU increased when cells were treated with 5-FU for 2 days (Fig. 4F). By contrast, the cell inhibition rates were reduced in CRC cells overexpressing BLACAT2 when treated with 5-FU for 2 days (Fig. 4G). These findings suggested that BLACAT2 contributed to the proliferation and chemoresistance of CRC cells.

\section{Discussion}

The function of lncRNAs has been extensively investigated in recent years, and lncRNAs are emerging from the 'desert region' of the genome as a novel source of biomarkers to characterize disease recurrence and progression, since a number of lncRNAs have restricted species-specific and cancer-specific expression patterns (12). The first CRC-associated IncRNA was identified in 1996 when Hibi et al (13) reported that the endogenous H19 imprinted maternally expressed transcript (H19) gene is frequently abundant in CRC specimens, and overexpression of H19 serves an important role in CRC development. A recent study demonstrated that lncRNAs serve pivotal roles in invasion, metastasis, early diagnosis, prognosis, chemoresistance and radioresistance of CRC (14). Since the 1950s, 5-FU-based chemotherapy has been a fundamental method for the treatment of patients with CRC (15). However, a previous 
A

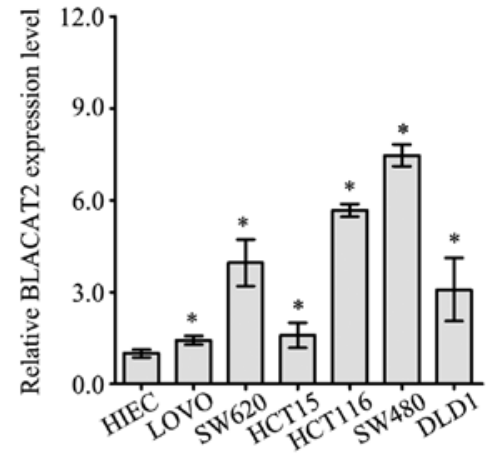

$\mathrm{C}$

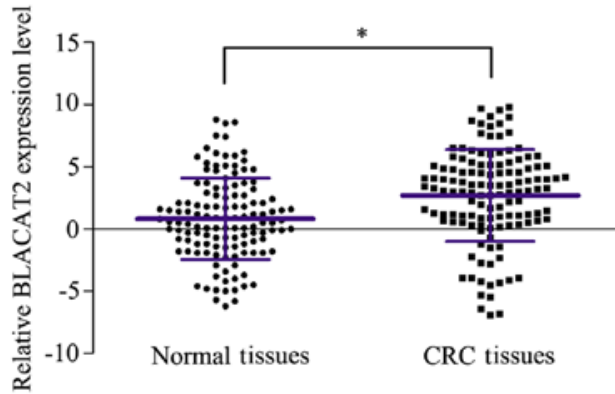

$\mathrm{E}$

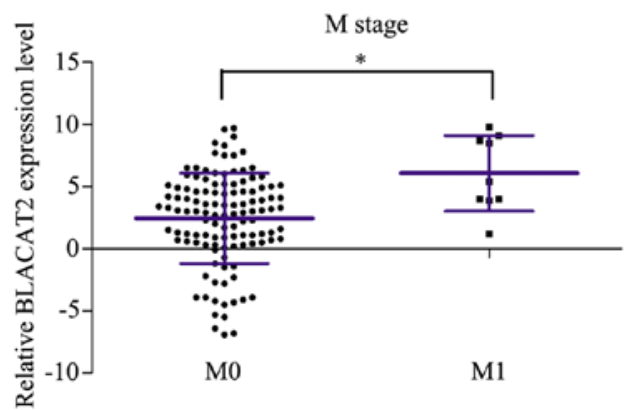

B

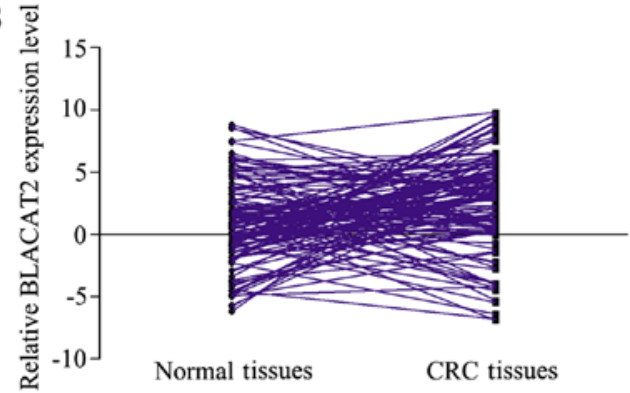

$\mathrm{D}$

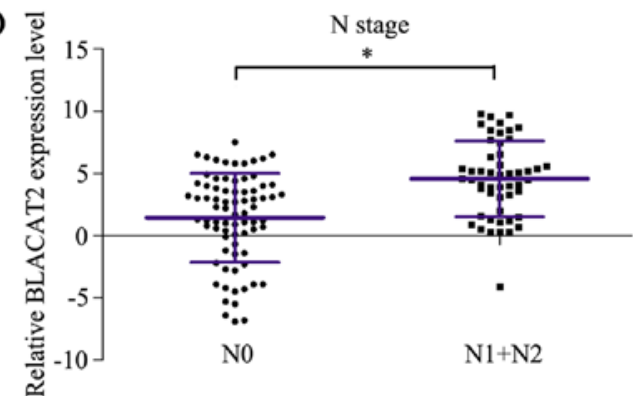

$\mathrm{F}$

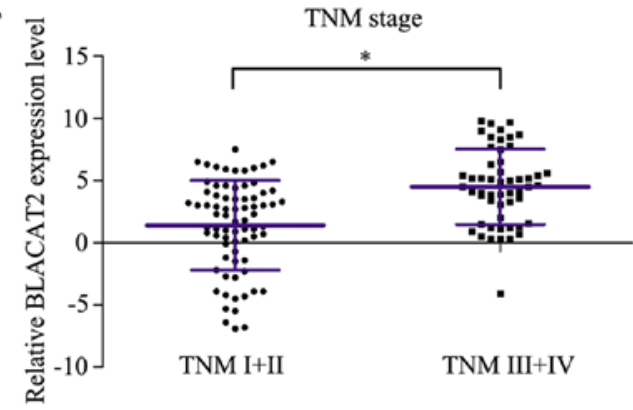

Figure 1. Long non-coding RNA BLACAT2 overexpression is associated with CRC clinical progression. (A) Expression levels of BLACAT2 were measured in CRC cell lines and HIEC cells by RT-qPCR assay. (B) Expression levels of BLACAT2 were detected in 127 CRC tissues and the corresponding normal tissues by RT-qPCR assay. (C) Statistical analysis of the relative expression levels of BLACAT2 in 127 CRC tissues and corresponding normal tissues. (D) Statistical analysis of the relative expression levels of BLACAT2 in CRC tissues with $(\mathrm{N} 1+2)$ or without (N0) lymph node metastasis. (E) Statistical analysis of the relative expression levels of BLACAT2 in CRC tissues with (M1) or without (M0) distant metastasis. (F) Statistical analysis of the relative expression levels of BLACAT2 in CRC tissues in early (TNM I +II) and advanced stages (TNM III+IV). "P<0.05. BLACAT2, bladder cancer-associated transcript 2; CRC, colorectal cancer; M, metastasis; N, lymph node stage; RT-qPCR, reverse transcription-quantitative polymerase chain reaction; TNM, tumor-node-metastasis.
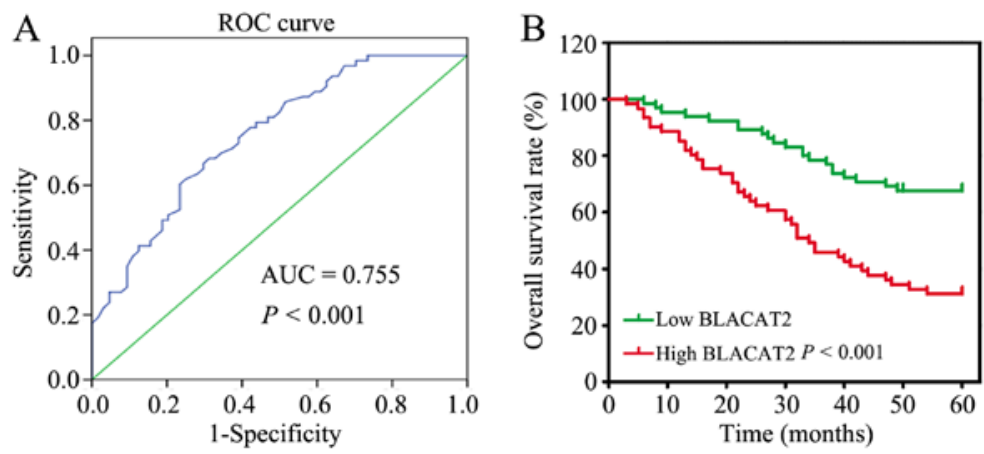

Figure 2. High long non-coding RNA BLACAT2 expression predicts poor OS in patients with CRC. (A) ROC curve analysis was utilized to define the cut-off point for high or low BLACAT2 expression for the OS analysis in patients with CRC. (B) Kaplan-Meier analysis and log-rank test were performed to investigate the OS differences between the low and high BLACAT2 expression groups. AUC, area under the curve; BLACAT2, bladder cancer-associated transcript 2; CRC, colorectal cancer; OS, overall survival; ROC, receiver operating characteristic.

study revealed that almost half of all patients with metastatic CRC are resistant to 5-FU-based chemotherapy (16). Therefore, further investigations to reveal the chemoresistant mechanisms in CRC are required. The results of the present study revealed a potential role of BLACAT2 in contributing to chemoresistance of CRC cells. 
Table II. Statistical analysis of risk factors for overall survival of patients with colorectal cancer.

\begin{tabular}{|c|c|c|c|}
\hline Parameters & Hazard ratio & $95 \%$ Confidence interval & P-value \\
\hline Age ( $<60$ years vs. $\geq 60$ years $)$ & 0.800 & $0.488-1.313$ & 0.378 \\
\hline Sex (male vs. female) & 0.951 & $0.580-1.560$ & 0.844 \\
\hline CEA level $(<4.5 \mu \mathrm{g} / \mathrm{ml}$ vs. $>4.5 \mu \mathrm{g} / \mathrm{ml})$ & 1.631 & $0.987-2.695$ & 0.056 \\
\hline Tumor location (colon vs. rectum) & 1.013 & $0.609-1.686$ & 0.959 \\
\hline Differentiation (Poor + Undifferentiated vs. Well + Moderate) & 1.530 & $0.933-2.508$ & 0.092 \\
\hline Tumor size ( $\geq 5 \mathrm{~cm}$ vs. $5 \mathrm{~cm}$ ) & 0.743 & $0.442-1.248$ & 0.261 \\
\hline T stage $(\mathrm{T} 1+\mathrm{T} 2$ vs. $\mathrm{T} 3+\mathrm{T} 4)$ & 0.998 & $0.609-1.637$ & 0.994 \\
\hline N stage (N1 vs. N0) & 4.917 & $2.918-8.285$ & $<0.001$ \\
\hline M stage (M1 vs. M0) & 5.751 & $2.731-12.110$ & $<0.001$ \\
\hline TNM stage (III+IV vs. I+II) & 5.422 & $3.179-9.247$ & $<0.001$ \\
\hline BLACAT2 (high vs. low) & 1.273 & $1.165-1.391$ & $<0.001$ \\
\hline
\end{tabular}

BLACAT2, bladder cancer-associated transcript 2; CEA, carcinoembryonic antigen; M, metastasis; N, node; T, tumor.
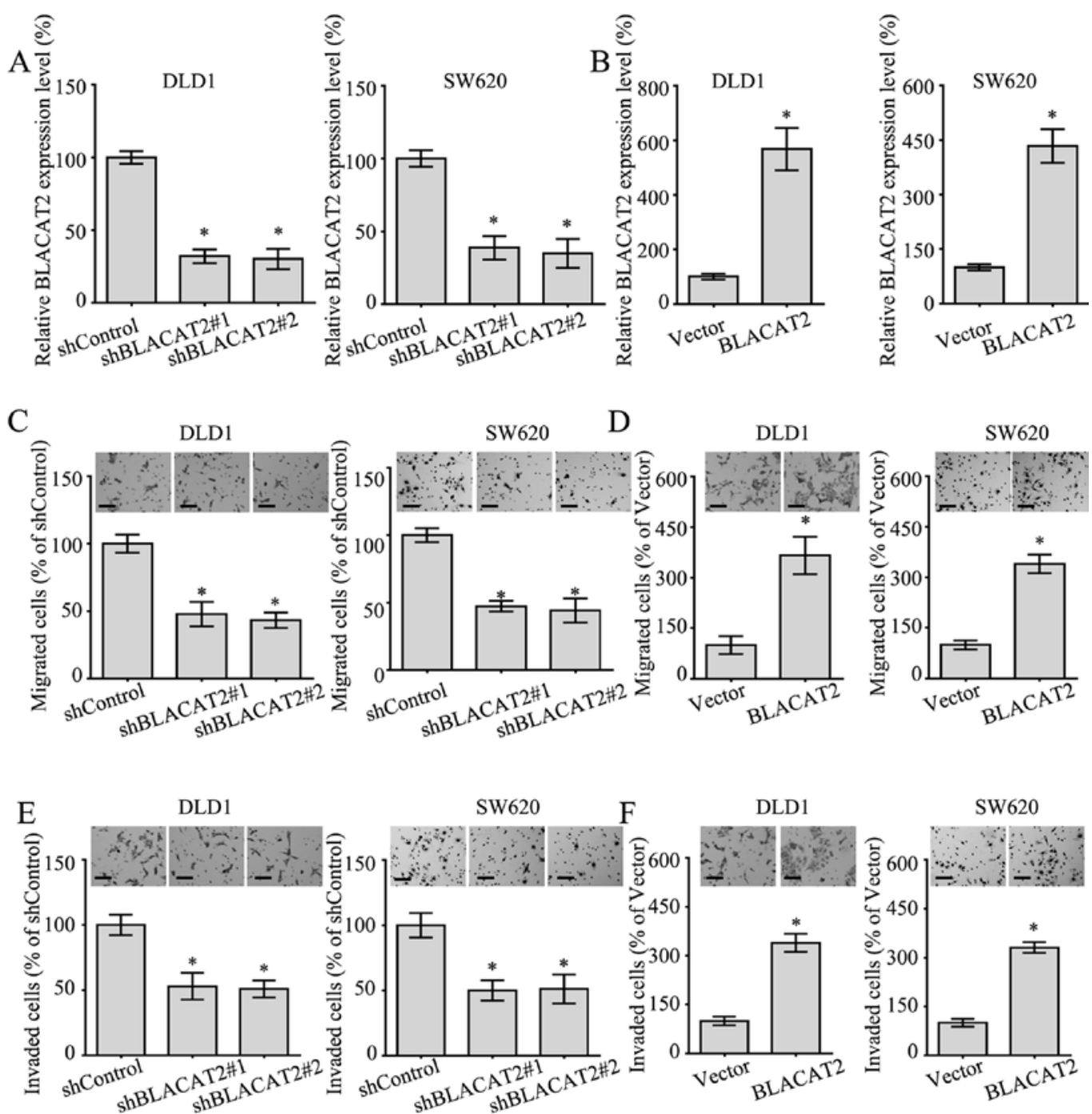

Figure 3. Long non-coding RNA BLACAT2 accelerates the migration and invasion of colorectal cancer cells. (A) Relative expression levels of BLACAT2 in DLD1 and SW620 cells transfected with shControl, shBLACAT2\#1 and shBLACAT2\#2 detected by RT-qPCR assay. (B) Relative expression levels of BLACAT2 in DLD1 and SW620 cells transfected with empty vector or BLACAT2 overexpression plasmid detected by RT-qPCR assay. (C) Migration of DLD1 and SW620 cells with BLACAT2 deficiency measured by Transwell assay. Scale bars, $50 \mu \mathrm{m}$. (D) Migration of DLD1 and SW620 cells with BLACAT2 overexpression measured by Transwell assay. Scale bars, $50 \mu \mathrm{m}$. (E) Invasive capacity of DLD1 and SW620 cells with BLACAT2 deficiency measured by Matrigel assay. Scale bars, $50 \mu \mathrm{m}$. (F) Invasive capacity of DLD1 and SW620 cells with BLACAT2 overexpression measured with a Matrigel assay. Scale bars, $50 \mu \mathrm{m}$. ${ }^{*} \mathrm{P}<0.05$. BLACAT2, bladder cancer-associated transcript 2; RT-qPCR, reverse transcription-quantitative polymerase chain reaction; sh, short hairpin RNA. 
A

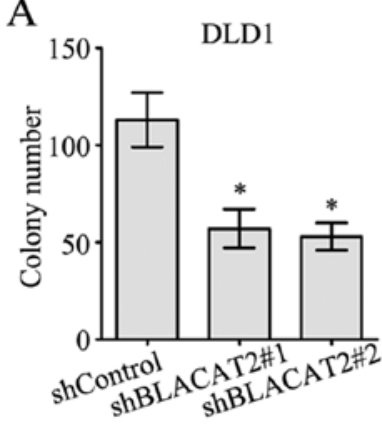

$\mathrm{C}$
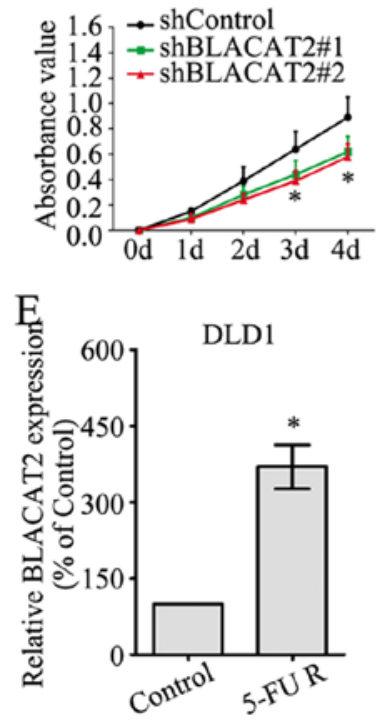

$\mathrm{F}$

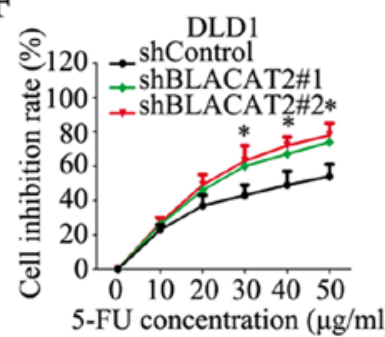

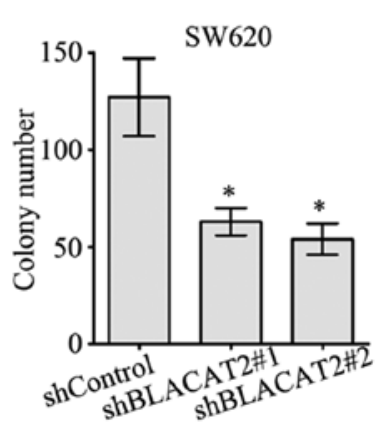

B
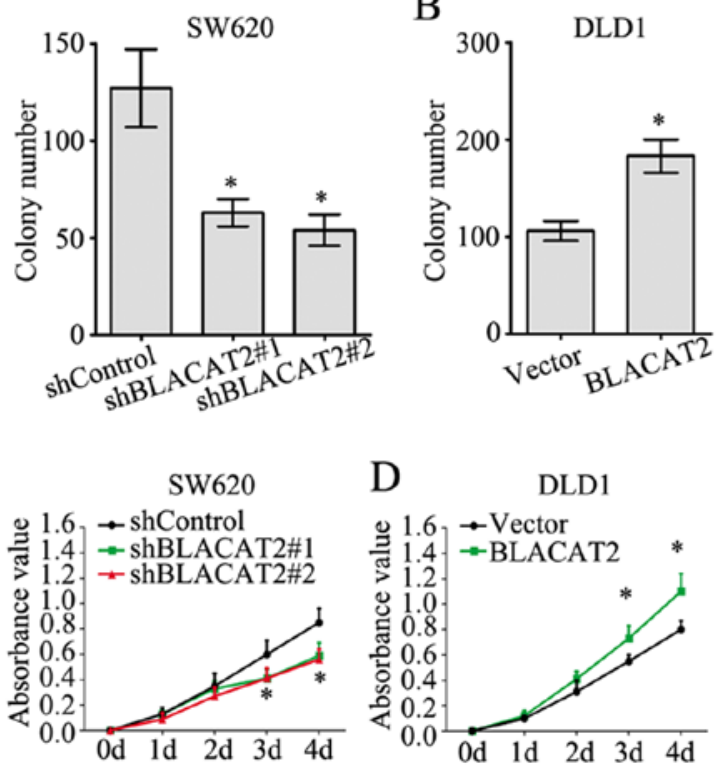

SW620
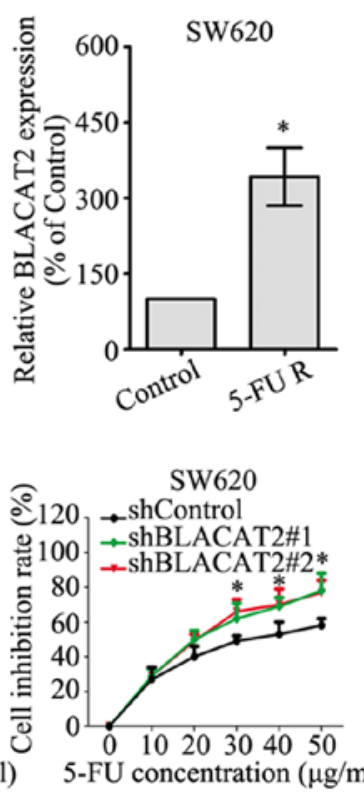
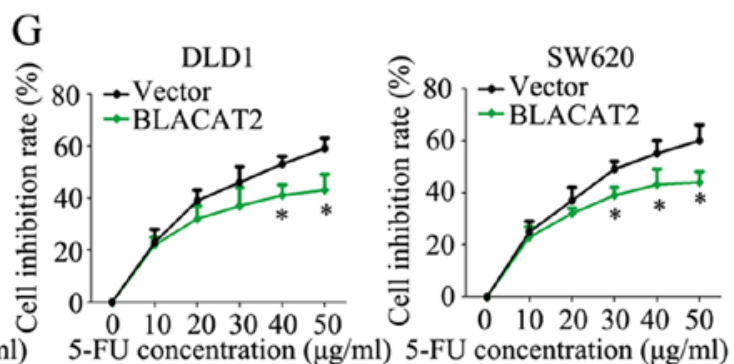

Figure 4. Long non-coding RNA BLACAT2 promotes proliferation and chemoresistance in colorectal cancer cells. (A) Number of colonies formed in DLD1 and SW620 cell lines following BLACAT2 downregulation. (B) Number of colonies formed in DLD1 and SW620 cell lines following BLACAT2 upregulation. (C) Absorbance values of DLD1 and SW620 cells following BLACAT2 knockdown in the MTT assay. (D) Absorbance values of DLD1 and SW620 cells following BLACAT2 overexpression in the MTT assay. (E) Expression levels of BLACAT2 in DLD1 cells, SW620 cells and corresponding 5-FU R cells measured by a reverse transcription-quantitative polymerase chain reaction assay. (F) An MTT assay was conducted to detect the cell inhibition rate of DLD1 and SW620 cells following BLACAT2 knockdown with different 5-FU concentrations. (G) An MTT assay was conducted to detect the cell inhibition rate of DLD1 cells and SW620 cells following BLACAT2 overexpression with different 5-FU concentrations. * P<0.05, compared with the control group. 5-FU, 5-fluorouracil; BLACAT2, bladder cancer-associated transcript 2; R, resistant; sh, short hairpin RNA.

Mechanistically, IncRNAs affect CRC progression by functioning as precursors of microRNAs or competing with endogenous RNAs, interacting with proteins and regulating epigenetic mechanisms (17). For example, the lncRNA metastasis-associated lung adenocarcinoma transcript 1 can competitively bind to the tumor suppressor splicing factor proline and glutamine rich (SFPQ) gene and release SFPQ from the SFPQ/polypyrimidine tract binding protein 2 complex, thus promoting the growth and migration of CRC cells (18). The lncRNA colorectal neoplasia differentially expressed may regulate the progression and chemoresistance of CRC by binding
microRNA (miRNA)-181a-5p and modulating its expression and subsequently mediating the activity of the Wnt/B-catenin signaling pathway (19). The lncRNA ubiquitin-like with plant homeodomain and really interesting new gene finger domains 1 protein associated transcript may interact with and stabilize the epigenetic factor ubiquitin like with PHD and ring finger domains 1 by interfering with its $\beta$-transducin repeat-containing protein mediated ubiquitination, which promotes the survival and tumorigenicity of CRC cells (20).

It has been verified that BLACAT2 is upregulated in bladder cancer, is correlated with lymph node metastasis, and 
induces lymphangiogenesis in vitro and in vivo (9). In addition, BLACAT2 was demonstrated to epigenetically increase vascular epidermal growth factor C (VEGF-C) expression by directly associating with WD repeat domain 5 (WDR5), a core subunit of the human H3K4 methyltransferase complexes (9). Therefore, expression of VEGF-C and WDR5 could be further investigated in CRC cells with BLACAT2 overexpression or knockdown to elucidate the possible mechanisms of BLACAT2. In addition, numerous mechanisms have been reported in the field of IncRNA-mediated cancer biology, including influencing chromatin state and methylation, and the stability of proteins and complexes or by acting as a sponge for miRNA inhibition (21). Epigenetic remodeling is frequently achieved through the interaction of a lncRNA with polycomb repressive complex 2 , a protein from the polycomb complex that induces chromatin inactivation by establishing inhibitory H3K427me3 histone signals $(22,23)$. Certain lncRNAs recruit DNA methyltransferases directly to modify chromatin conformation, or they modify nucleosome positioning. In addition, numerous lncRNAs exert their oncogenic function through direct interaction with proteins or protein complexes as scaffolds or allosteric activators/inhibitors (24-28). Furthermore, some lncRNAs have recently been revealed to act as competing endogenous RNAs by binding miRNAs ('sponging'), and reducing their inhibitory effect on their natural targets (29-31). Potential targeting miRNAs could be predicted with bioinformatics methods, and further experiments, such as a dual luciferase assay, are required to verify the potential targets. Information regarding BLACAT2 is limited since it is a novel lncRNA; therefore, further investigations are required to determine its significance.

The present study aimed to define the clinical significance and functional role of BLACAT2 in CRC. Notably, BLACAT2 may function as an oncogene in CRC and may be associated with $\mathrm{CRC}$ clinicopathological progression as reported in bladder cancer (9). To determine the cutoff value of the BLACAT2 expression level, a ROC curve was utilized. Notably, the area under the curve was 0.755 , with a P-value $<0.001$, which suggested that BLACAT2 may be a promising diagnostic marker for CRC. Based on the cutoff value obtained from ROC curve analysis, statistical analysis of clinicopathological features was carried out to compare the high and low BLACAT2 expression groups. Notably, high BLACAT2 expression was associated with larger tumor size $(\mathrm{P}=0.029)$, more advanced $\mathrm{N}$ stage $(\mathrm{P}<0.001), \mathrm{M}$ stage $(\mathrm{P}=0.028), \mathrm{TNM}$ stage $(\mathrm{P}<0.001)$ and poor $\mathrm{OS}(\mathrm{P}<0.001)$, all of which are fundamental factors in evaluating the clinical progression of CRC. Additionally, univariate and multivariate analyses further identified high BLACAT2 expression as an independent survival risk factor for patients with $\mathrm{CRC}(\mathrm{P}=0.001)$, which suggested a prognostic value of BLACAT2 in patients with CRC. Furthermore, BLACAT2 was demonstrated to promote the proliferation, metastasis and chemoresistance of CRC cells, which further confirmed the pivotal role of BLACAT2 in CRC biology.

In conclusion, the present study verified the oncogenic role of BLACAT2 in CRC. However, the detailed mechanisms by which BLACAT2 promoted CRC progression and chemoresistance require further exploration, and more evidence is required to confirm the results of the present study. The results suggested that BLACAT2 may be a potential prognostic marker and therapeutic target in CRC.

\section{Acknowledgements}

Not applicable.

\section{Funding}

The present study was supported by the Nanchong Natural Science Fund Project (grant no. 16YFZJ0054) and the Sichuan Provincial Natural Science Foundation (grant no. 17ZB0169).

\section{Availability of data and materials}

The datasets used and/or analyzed during the present study are available from the corresponding author on reasonable request.

\section{Authors' contributions}

YR designed the study, measured the expression of BLACAT2 in tissues, performed some of the in vitro experiments and revised the manuscript. $\mathrm{CZ}$ and $\mathrm{YH}$ collected the tissues, conducted some of the in vitro assays and drafted the manuscript. HX and XM performed the statistical analysis of the data and conducted the follow-up of the patients. All authors approved the final manuscript.

\section{Ethics approval and consent to participate}

Written informed consent was obtained from all patients. The present study was approved by the Ethics Committee of The Affiliated Hospital of North Sichuan Medical College.

\section{Patient consent for publication}

Written informed consent was obtained from all patients.

\section{Competing interests}

The authors declare that they have no competing interests.

\section{References}

1. Siegel RL, Miller KD and Jemal A: Cancer statistics, 2016. CA Cancer J Clin 66: 7-30, 2016.

2. Esin E and Yalcin S: Maintenance strategy in metastatic colorectal cancer: A systematic review. Cancer Treat Rev 42: 82-90, 2016.

3. van der Stok EP, Spaander MCW, Grunhagen DJ, Verhoef C and Kuipers EJ: Surveillance after curative treatment for colorectal cancer. Nat Rev Clin Oncol 14: 297-315, 2017.

4. Jarroux J, Morillon A and Pinskaya M: History, discovery, and classification of lncRNAs. Adv Exp Med Biol 1008: 1-46, 2017.

5. Rinn JL and Chang HY: Genome regulation by long noncoding RNAs. Annu Rev Biochem 81: 145-166, 2012.

6. Kwok ZH and Tay Y: Long noncoding RNAs: Lincs between human health and disease. Biochem Soc Trans 45: 805-812, 2017.

7. Rao AKDM, Rajkumar T and Mani S: Perspectives of long non-coding RNAs in cancer. Mol Biol Rep 44: 203-218, 2017.

8. Chandra Gupta S and Nandan Tripathi Y: Potential of long non-coding RNAs in cancer patients: From biomarkers to therapeutic targets. Int J Cancer 140: 1955-1967, 2017. 
9. He W, Zhong G, Jiang N, Wang B, Fan X, Chen C, Chen X, Huang $\mathrm{J}$ and Lin T: Long noncoding RNA BLACAT2 promotes bladder cancer-associated lymphangiogenesis and lymphatic metastasis. J Clin Invest 128: 861-875, 2018.

10. Weiser MR: AJCC 8th edition: Colorectal cancer. Ann Surg Oncol 25: 1454-1455, 2018

11. Livak KJ and Schmittgen TD: Analysis of relative gene expression data using real-time quantitative PCR and the 2(-Delta Delta C(T)) method. Methods 25: 402-408, 2001.

12. Han D, Wang M, Ma N, Xu Y, Jiang Y and Gao X: Long noncoding RNAs: Novel players in colorectal cancer. Cancer Lett 361: 13-21, 2015.

13. Hibi K, Nakamura H, Hirai A, Fujikake Y, Kasai Y, Akiyama S, Ito $\mathrm{K}$ and Takagi $\mathrm{H}$ : Loss of $\mathrm{H} 19$ imprinting in esophageal cancer. Cancer Res 56: 480-482, 1996.

14. Luo J, Qu J, Wu DK, Lu ZL, Sun YS and Qu Q: Long non-coding RNAs: A rising biotarget in colorectal cancer. Oncotarget 8: 22187-22202, 2017.

15. Showalter SL, Showalter TN, Witkiewicz A, Havens R, Kennedy EP, Hucl T, Kern SE, Yeo CJ and Brody JR: Evaluating the drug-target relationship between thymidylate synthase expression and tumor response to 5-fluorouracil. Is it time to move forward? Cancer Biol Ther 7: 986-994, 2008.

16. Douillard JY, Cunningham D, Roth AD, Navarro M, James RD, Karasek P, Jandik P, Iveson T, Carmichael J, Alakl M, et al: Irinotecan combined with fluorouracil compared with fluorouracil alone as first-line treatment for metastatic colorectal cancer: A multicentre randomised trial. Lancet 355: 1041-1047, 2000.

17. Weng M, Wu D, Yang C, Peng H, Wang G, Wang T and Li X: Noncoding RNAs in the development, diagnosis, and prognosis of colorectal cancer. Transl Res 181: 108-120, 2017.

18. Ji Q, Zhang L, Liu X, Zhou L, Wang W, Han Z, Sui H, Tang Y, Wang Y and Liu N: Long non-coding RNA MALAT1 promotes tumour growth and metastasis in colorectal cancer through binding to SFPQ and releasing oncogene PTBP2 from SFPQ/PTBP2 complex. Br J Cancer 111: 736-748, 2014

19. Han P, Li JW, Zhang BM, Lv JC, Li YM, Gu XY, Yu ZW, Jia YH, Bai XF, Li L, et al: The lncRNA CRNDE promotes colorectal cancer cell proliferation and chemoresistance via miR-181a-5p-mediated regulation of $\mathrm{Wnt} / \beta$-catenin signaling. Mol Cancer 16: 9, 2017.
20. Taniue K, Kurimoto A, Sugimasa H, Nasu E, Takeda Y, Iwasaki K, Nagashima T, Okada-Hatakeyama M, Oyama M, Kozuka-Hata $\mathrm{H}$, et al: Long noncoding RNA UPAT promotes colon tumorigenesis by inhibiting degradation of UHRF1. Proc Natl Acad Sci USA 113: 1273-1278, 2016.

21. Bartonicek N, Maag JL and Dinger ME: Long noncoding RNAs in cancer: Mechanisms of action and technological advancements. Mol Cancer 15: 43, 2016.

22. Ringrose L, Ehret $\mathrm{H}$ and Paro R: Distinct contributions of histone $\mathrm{H} 3$ lysine 9 and 27 methylation to locus-specific stability of polycomb complexes. Mol Cell 16: 641-653, 2004.

23. Davidovich $C$ and Cech TR: The recruitment of chromatin modifiers by long noncoding RNAs: Lessons from PRC2. RNA 21: 2007-2022, 2015

24. Takayama K, Horie-Inoue K, Katayama S, Suzuki T, Tsutsumi S, Ikeda K, Urano T, Fujimura T, Takagi K, Takahashi S, et al: Androgen-responsive long noncoding RNA CTBP1-AS promotes prostate cancer. EMBO J 32: 1665-1680, 2013.

25. Li Y, Wang Z, Shi H, Li H, Li L, Fang R, Cai X, Liu B, Zhang X and Ye L: HBXIP and LSD1 scaffolded by lncRNA hotair mediate transcriptional activation by c-Myc. Cancer Res 76: 293-304, 2016

26. Rippe K and Luke B: TERRA and the state of the telomere. Nat Struct Mol Biol 22: 853-858, 2015.

27. Mourtada-Maarabouni M, Pickard MR, Hedge VL, Farzaneh F and Williams GT: GAS5, a non-protein-coding RNA, controls apoptosis and is downregulated in breast cancer. Oncogene 28: 195-208, 2009.

28. Wang G, Lunardi A, Zhang J, Chen Z, Ala U, Webster KA, Tay Y, Gonzalez-Billalabeitia E, Egia A, Shaffer DR, et al: Zbtb7a suppresses prostate cancer through repression of a Sox9-dependent pathway for cellular senescence bypass and tumor invasion. Nat Genet 45: 739-746, 2013.

29. Tay Y, Rinn J and Pandolfi PP: The multilayered complexity of ceRNA crosstalk and competition. Nature 505: 344-352, 2014.

30. Nie W, Ge HJ, Yang XQ, Sun X, Huang H, Tao X, Chen WS and Li B: LncRNA-UCA1 exerts oncogenic functions in non-small cell lung cancer by targeting miR-193a-3p. Cancer Lett 371: 99-106, 2016.

31. Zhou X, Gao Q, Wang J, Zhang X, Liu K and Duan Z: Linc-RNA-RoR acts as a 'sponge' against mediation of the differentiation of endometrial cancer stem cells by microRNA-145. Gynecol Oncol 133: 333-339, 2014. 